\title{
Improvisational Artistry in Live Dance Performance as Embodied and Extended Agency
}

\author{
Aili Bresnahan
}

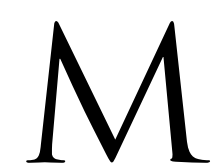

$y$ aims in this article are twofold: (1) to provide an account of improvisational artistry on the part of the dancer during the course of live dance performance, and (2) to show how Andy Clark's embodied and extended mind theory can flesh out the cognitive and physiological basis for the agency involved in this improvisational artistry (see Clark 2011). Clark is a philosopher of mind who holds the view that "mind" should refer not just to the brain and neural system, but to the body and to those components of the world outside of the body that become part of our thought process through a system of complex and engaged interactions. My claim is that "improvisational artistry" - that sort of thinking-while-doing that all dance performers engage in during the course of live dance performance that is not limited to any particular forms of improvisation-can be elucidated with respect to this theory. I do not go so far as to say that improvisational artistry is "thinking," but make the weaker claim that it can be construed as a type of "agency" that can benefit from Clark's philosophical framework without making a commitment to any theory of what counts as "mind" or "thought."

Clark does not specifically address dance improvisation or style, so what I propose here is an extension of his views on dance. First, I will provide a general overview of current theories of dance improvisation in order to show how my account supplements those theories. I will also discuss expression and style as an important aspect of the type of broad-based improvisational activity that I will develop in this article, which I will describe as a kind of body- and environment-involved agency that includes all the style-informed ways that a dancer moves in response to the contingencies and needs of the performance environment and artistic purposes of the dance. Second, I will outline the basics of Clark's embodied and extended mind theory, as well as set forth how the standard theory of mind differs from it and in some ways contradicts it. The purpose of considering it in light of the standard theory of mind is to show why I have chosen Clark's theory as a good fit for the minded agency I will describe that takes place as improvisational artistry rather than having recourse to the standard theory of mind. Third, I will present a theory of improvisational artistry in live dance performance that makes use of Clark's theory by considering his features of "mind" as part of the agency of the dance performer. ${ }^{1}$ My purpose in doing this is to expand the idea of what counts as "dance improvisation" in philosophical aesthetics by both updating it with current

Aili Bresnahan teaches philosophy, including the philosophy of dance, at the University of Dayton in Ohio. She grew up in New York City, where she attended the F.H. LaGuardia High School for Music and the Arts, and where she trained to be a professional ballet dancer. Bresnahan went on to earn a bachelor's degree in philosophy from Columbia University in New York, a law degree from Georgetown University Law Center in Washington, DC, and a PhD in philosophy from Temple University in Philadelphia. She is also the founder and moderator of the DancePhilosophers Google group, an informal and interdisciplinary networking group for researchers in the philosophy of dance broadly construed. 
theories of improvisation in dance studies and by adding an "embodied and extended" dimension to these theories.

I define agency here in a broad sense-as the control and intention the dance performer has to move in a certain way, whether cognized specifically or not. Agency would include almost everything pertaining to a dance performer's intentional movement, including neuromuscular awarenesses and responses. The limiting feature on this agency, which otherwise might be so broad as to lack value, is the dancer's training in learned and individual styles. The dancer is not free to just do anything, but has a repertoire of learned and instinctual movements from which to choose that affects his or her dance performance in artistically relevant ways. How this works, precisely, will be discussed more fully below.

Dance improvisation has been a neglected topic in philosophy publications, although dance studies, dance history, dance anthropology, and other fields of dance scholarship routinely discuss improvisation as a major part of dance innovation, practice, and performance. ${ }^{2}$ In 2000, a full issue of The Journal of Aesthetics and Art Criticism was devoted to the question of improvisation in the arts. In that issue, Curtis L. Carter provided the sole article on dance, with the majority of the articles contained in that issue focusing on improvisation in music (see Carter 2000). Carter characterizes improvisation in the arts in general as involving "suspension of set structures for a practice and the introduction of nontraditional elements. As a precondition improvisation thus requires the power to invent new forms spontaneously" (Carter 2000, 181). Carter then distinguishes improvisation in dance from improvisation in other arts such as music or painting by its involvement of the human body, "including the physical, conceptual, and emotional resources embodied in the body..." (Carter 2000, 182). Finally, Carter identifies what he says are three main types of improvisation in theater dance:

[1] The embellishments left to the individual artists where a set choreography persists

[2] Improvisation as a process of spontaneous free movement to invent original movement intended for use in set choreography

[3] Improvisation for its own sake that is brought to a high level of performance (Carter 2000, 182; bracketed numbers have been supplied)

In the remainder of the article, Carter then sets forth historical examples of each type of improvisation, demonstrating the ways that theater dance choreographers and dancers have incorporated each of these types in their practice and performance, and how these forms of improvisation have developed over the course of dance history (Carter 2000, 186).

Since that article appeared in 2000, there have been no other accounts of dance improvisation in philosophy publications that would amend this view. Dance studies, however, has offered some theories that can be used here to update his account. We might include another type, [4] improvisation performed in order to achieve a movement-based somatic state (De Spain 2003, 27-8). Here improvisation is used as a movement and bodily awareness research tool that is not necessarily linked to any particular dance performance for an audience.

We might also include [5] improvisation in "challenge dance" performances. Here the purpose is to win an ever-escalating competition of skill and style. Constance Valis Hill provides an overview of some of the forms of challenge-based improvisation in her article, "Stepping, Stealing, Sharing, and Daring" (2003). She includes tap dancing challenges, "jigging competitions" on plantations, challenge dances in the "walk-around" finale of minstrel shows, street dance and social club showdowns, and buck-and-wing dance competitions that occurred in vaudeville shows that were judged by juries (Hill 2003, 90). The purpose of these competitions was and is often to "steal" steps, movements, and styles from one's competitor and then "signify" by referring to one's opponent's best steps and then modifying and improving upon them in a spontaneous way (Hill 2003, 93). 
Danielle Goldman (2010) has an account of improvisation that can be used to augment Carter's overall idea that improvisation "requires the power to invent new forms spontaneously" (Carter 2000, 181). Goldman argues that one's "power" to invent improvisationally must be understood in light of one's social and historical position in the world (such as being a slave or otherwise oppressed, for example). Thus she shows that there are significant constraints placed upon one's literal and figurative ability to move that ought to be brought to bear on our understanding of the "freedom" that "spontaneity" implies (Goldman 2010, 5). This connects to the concept of agency at issue in this article: What constitutes the agency necessary for spontaneity in a moving, improvising person? For Goldman, environmental context is relevant in answering this question, including not just sociopolitical and historical constraints but any physical constraints that occur in the improvising environment (see Goldman 2010, 27). She concludes that "the practice of improvisation-the training that truly skillful improvisation requires-is a rigorous mode of making oneself ready for a range of potential situations. It is an incessant preparation, grounded in the present while open to the next moment's possible actions and constraints" (Goldman 2010, 142, emphasis in original).

Susan Leigh Foster agrees that "it is this suspense-filled plenitude of the not-quite-known that gives live performance its special brilliance" $(2003,4)$. In addition, Foster adds another nuance to this idea of spontaneity by introducing the notion that the kind of agency in improvisation resembles what she calls "the middle voice." When a dancer follows the middle voice, she is neither leading nor following but moving with either another dancer or with the flow of the dance (see Foster 2003, 8).

I argue that agency is limited not just by historical, political, and social constraints, but that it is also limited and enhanced by our trained and naturally developed abilities to engage with the world on the fly, thinking-while-doing. This "on-the-fly" activity can be construed as a sort of zone, flow, or "middle voice" kind of agency. It is this aspect of dance performance and the performer's ability to engage with and negotiate environmental and artistic constraints that requires an agency steeped in an improvisational artistry that is developed over the course of one's life. My claim is that dance performers always make improvisational contributions to a dance through all the activities required of live performers who must think-while-doing in a non-static context. But, how does a dancer select the right way to effectuate and perform a dance from his or her repertoire of possible movements?

\section{Expression and Style}

I turn now to an article by Mary Sirridge and Adina Armelagos, "The In's and Out's of Dance: Expression as an Aspect of Style" (1977). ${ }^{3}$ I have chosen this article even though it was written in the late 1970s because the unique way that they characterize style is consistent with an important component of what I mean to bring out about improvisation in live dance performance today. Sirridge and Armelagos identify "style" as a concept that connects the dancer's activity or agency with what is expressed by the dance (Sirridge and Armelagos 1977, 15). They reject both the classical view of expression in dance (that a dancer expresses his or her own feelings or emotions in dance) and what they call the "modified expression theory" (that holds that the dancer concentrates on expressing a particular feeling or emotion through dancing even if $s /$ he does not possess the feeling or emotion while dancing) (Sirridge and Armelagos 1977, 15-6). They reject both views because they do not agree that there must be an "everyday expressive behavioral interaction" between performer and audience. Instead, Sirridge and Armelagos hold that dance performance is a phenomenon that is at a remove from ordinary communicative discourse (Sirridge and Armelagos 1977, 16). Their preferred theory for expression in dance is from Nelson Goodman's Languages of Art, in which Goodman claims artistic expression takes place through the structure of a dance work of art that expresses those properties it exemplifies metaphorically (Sirridge and Armelagos 1977, 17; Goodman 1976, 85). For Goodman, all works of art, including structures of dance works of art, express through metaphorical exemplification (Goodman 1976, 86-95). What he means by this is that an art work "expresses" the properties the metaphorical 
example or symbol suggests. Thus for Goodman those dances that express music may express ideas like peace or pomp or passion through the structure (metaphorical example) of the dance work of art, which he thinks in this case would be the rhythmic patterns (Goodman 1976, 91).

I agree with Sirridge, Armelagos, and Goodman that what an audience perceives need not reflect what the dancer is feeling or thinking while dancing. A dancer may be suppressing worries about a loved one, or may be in physical pain due to a nagging injury or focused on a technical aspect of creating the expressive movement. Indeed, it is often necessary for the audience to be unaware of what the dancer is feeling or thinking or the illusion of the dance is ruined. However, to separate the metaphor-making, -creating, and/or -effectuating activity from the dancer and put it wholly into the "dance work of art" neglects an important aspect of the dance performer's role in a live dance performance. Dances are created, made, and enacted by the activity of dance choreographers and performers, with the role of the performer providing the crucial link between dance and audience that makes the latter's apprehension of the dance possible. In separating the dancer's feelings from the dance, perhaps Sirridge, Armelagos, and Goodman have gone too far in separating the dancer's agency from their account of expression and style in dance, losing this important aspect of dance performance in the process. ${ }^{4}$ Dance performances are not just appreciated by audiences for the metaphorical exemplification of a dance but are also often involved in watching and appreciating the process of improvisational artistry that takes place during a performance-in-progress.

The next part of Sirridge and Armelagos's essay turns to "style" as providing the mode by which dancers contribute to the efficacy (expression) of a dance's metaphorical exemplification. Here, Sirridge and Armelagos credit a codified dance style, such as classical ballet, with "providing the dancer with an inventory of movements or sequences of movements" that give him or her the "spatial vocabulary" necessary to exemplify the dance's metaphor (Sirridge and Armelagos 1977, 18). They call dancing in this sort of a style, one provided by a particular school or method, "style ${ }_{1}$." Sirridge and Armelagos then go on to call personal style "style 2 ," characterizing this second kind of style as "a dancer's characteristic articulation of a more general spatial vocabulary," explaining that "style ${ }_{2}$ thus supervenes on and implements" style ${ }_{1}$ in a personal way (Sirridge and Armelagos 1977, 19).

It is this account of two primary types of style, the kind that is learned in a school and the kind that is developed in a personal way by a dance performer, that will inform my account of "improvisational artistry" as conceived as a kind of embodied and extended agency. This concept will be addressed and expanded more fully in the Improvisational Artistry section below, so I ask the reader to bracket this idea until then. There I will show that, through style, both a dancer's individual nature and training can be re-integrated into an account of improvisation during live dance performance that can be conceived as a kind of artistic agency.

I turn now to how Clark's theory might help to explain the process of the agency involved in improvisational artistry during live dance performance.

\section{Clark's Embodied and Extended Mind Theory}

Embodied and extended mind hypotheses in the philosophy of mind hold that certain kinds of action, such as developed motor activities, are best understood from a perspective that considers the mind to extend beyond the borders of the brain and the neural system. On this view, "mind" (1) is not reducible to brain and (2) is the locus of thought that is constrained and enabled both by bodily and environmental processes that occur in a context in which these processes interact in a symbiotic relationship. I have chosen Clark's particular version of an embodied and extended mind view to use here because it is both clear and ready-to-hand as an extension of the concept 
of improvisational artistry I have in mind. ${ }^{5}$ Clark agrees with standard mind theorists that cognition does have an "inner core" comprising the brain and neural system, but he disagrees with them in his claim that to understand many thought processes one needs to understand how external features and agents can act as the "supervenience base" for this core, by which he means that the external components are the primary, base materials from which a complex thought process can emerge. In addition, Clark conceives of "thought" as a systemic unification of all of the features that are integral to its content and not just what can be attributed to the brain and neural system in an abstraction away from this system and process.

In order to better understand how Clark's embodied and extended mind theory offers resources for addressing the question of how we can account for the improvisational artistry that takes place during live dance performance, a short detour into the basics of his theory is necessary. Not all of this will be of interest to the reader who is primarily interested in dance improvisation, but to truncate the theory too much runs the risk of misrepresenting his view. The reader who is not interested in more detail on Clark's view in contrast with the standard philosophy of mind can skip to the Improvisational Artistry section below, accordingly.

Clark credits John Haugeland with the assertion that mind, body, and world are not separated but instead have "close coupling and functional unity.... Mind, therefore, is not incidentally but intimately embedded in its world (Clark 2011, xxvii, quoting Haugeland 1998, 236-7)." Clark does not deny but rather seeks to augment the components of the standard view that characterize mind as a thinking or representing thing, holding that his extended mind theory "is committed only to the much weaker claim that some of the thinking, and even the representing, may supervene on activities and encodings that criss-cross brain, body, and world" (Clark 2011, 149). Further, for Clark, this supervenience is constitutive of the cognitive process it identifies in some way and is not merely instrumental. What this means is that the body and world comprise an integral part of the "participant machinery" on which various mental states and process can supervene (Clark 2011, 207).

In short, Clark's embodied and extended mind theory is a "distributed cognition theory" in which thought is initiated by an interior "core" that then involves and makes use of "feedback loops" in couplings and other partnerships with exterior processes (see Clark 2011, 108). Clark begins by extending mind beyond the borders of the brain to the body in a number of different ways. Here Clark's primary point is that embodiment is required in order for human agents to develop their cognitive capacities. Examples of active bodily processes that allow cognition to develop in this way include locomotion and modes of physical and sensory interaction with the world and with other people (see Clark 2011, ch. 1).

For Clark, then, embodied processes are thus incorporated into the brain and neural system's "thinking." He illustrates this point by demonstrating how we use the body schema, a term that he says "names a suite of neural settings that implicitly (and nonconsciously) define a body in terms of its capabilities for action, for example, by defining the extent of 'near space' for action programs" (Clark 2011, 39). Clark's claim here is that a body schema cannot develop unless the thinking agent is moving and interacting in a body and whose agency is not conceived as limited to a set of neurons. Clark considers this to be an "incorporation" of the body (rather than mere "use" of the body) because what emerges from the use of his or her environmental resources is not an independently enhanced brain, but a new, integrated, brain-neural-system-body process $(2011,39)$.

Clark then shows how mind extends beyond the body, including "actions and loops through nonbiological structures," that are not all interior $(2011,85)$. Clark thinks that internal core processes "incorporate" external conditions and processes, which means that on his view, "mind" can be controlled from "within" even though some of the features of this mind are biologically external (see Clark 2011, 39). Clark also holds the position that nonbiological environmental tools (such as a notebook to aid memory) can extend our body schemas and/or schema-involved cognitive 
processes, particularly where such a tool is used as part of an integrated mind-body activity (see Clark 2011, 228-30). David Chalmers has argued that Clark's view can thus be seen as just an extension of certain tenets of the traditional view of mind so that it is more inclusive of exterior forces (see Chalmers's Introduction to Clark 2011). Traditional mind theorists, however, tend not to agree with Chalmers here that Clark's view does not directly oppose their own (see, for example, Fodor 2009).

There is not space in the confines of this article to delve deeply into those theories of mind that directly oppose embodied and extended mind theories like Clark's, but I will outline some of these theories briefly below. John Searle $(1983,154)$, for example, holds that "mental" states are those that are "underived" and thus completely separable from our bodies and environment. Jerry Fodor (2009, 13-5) holds that the "mark of the mental" is intensionality with an " $\mathrm{s}$ "-the idea that mental states must be able to have content that is cognizable in an interior, reflexive way to be appropriately considered as part of mind. He also holds, and Daniel Dennett agrees, that the mind's proper function is computational and representational (see Fodor 1975; Dennett 1981). Patricia Churchland $(2002,1)$ claims that it is only the physical brain that feels, thinks, and decides, and the brain should be considered "mind."

No attempt will be made here to prove that these theories are false or show why they could not provide the basis for an alternative account of improvisation in dance performance. ${ }^{6}$ My point is merely to demonstrate that Clark's theory contains rich resources for addressing the question of how dance performers are able to integrate bodily processes and environmental awareness into their spontaneous agency during live performance that the standard mind theory neglects. The standard theory of mind simply does not offer enough guidance for the philosopher of dance who seeks to understand how the dancer's body and environment affects his or her improvisational activity in a crucial way. The standard mind theory suggests a theory of a performing dancer's agency in which the dancer's physical body is conceived as an instrument that is directed by his or her brain and neural system. But this contradicts many phenomenological accounts offered by dancer and choreographers. Ruth Zaporah, for example, says that in her improvisational work during live dance performance the content of her dances arise unbidden $(2003,24)$. If the standard mind theory is applied to a model of improvisational agency, it suggests that a dancer makes a decision about what movements to perform based upon some view about the dance and what is required by it and then decides to execute those movements. This, too, contradicts many important phenomenological accounts of dances and choreographers engaged in improvisation. Kent De Spain, for example, claims that in dance improvisation, one feels that the body has its own intentionality $(2003,34)$. In short, there is a gap between the standard theory of mind and the phenomenological experience of dance improvisation by dance performers and practitioners that needs to be overcome if we are to understand how the agency of live dance performance works. Clark's theory allows us to bridge that gap in a way that the standard theories of mind do not.

If a dancer's body is merely an instrument and all dance movements are effectuated "decisions" of some sort, how can the standard mind theory account for the cases of dance-making and doing where there is no pre-cognized plan? Even if such a plan exists, what if the performer is unable or unwilling to execute it as preconceived because of some contingency in the live performance environment? What if, for example, the dancer gets injured during the performance and cannot complete the scored movement? What if the dancer's costume headpiece comes loose during the performance and she has to either modify the planned head tilt or send the headpiece crashing to the ground? What if the conductor chooses a faster tempo than planned for the movement and so that the dance has to be sped up accordingly? Lastly, what if the choreographer has asked the dancer not to preplan the stylistic elements of final movement, in the hopes of creating an excitement and novelty that the audience can grasp as an on-the-spot addition at the dance performer's whim? Any of these contingencies_of the dancer's body, the performance environment, or the need to integrate thought and movement extremely quickly-may not allow for pre-planning, 
or fully cognized and brain-mediated computational and representational thought. It is thus not easy to see how recourse to the standard theory of mind can illuminate the special type of bodyand environment-involved improvisational agency that is involved during live dance performance.

I am not ready to follow Clark so far as to call everything that goes into a dancer's improvisational activity a product of "mind." Instead the term "agency" as it is used here incorporates everything Clark is calling "mind." It includes the extra-brain-and-neural-system contingencies found in one's body, instruments, accessories, and environment into the toolbox that a dance performer has at his or her disposal when improvising in live dance performance.

We turn now to how, exactly, the dancer might achieve his or her artistic aims through improvisational artistry in live dance performance in a way that (1) expands the type of improvisation involved within all dance performance through the use of style and (2) makes use of Clark's theory in order to explain how the agency involved in this artistry might work.

\section{Improvisational Artistry in Live Dance Performance as "Embodied and Extended Agency"}

My account of improvisational artistry involves a dancer's agency during the course of performing for a live audience. It is a sort of spontaneous agency that involves both conscious and spontaneous artistic choices that take place during performance. It is also derived from natural and cultural abilities, both of which include motor and cognitive capabilities, some of which may be combined together in the "agency" described earlier.

When dancers perform a dance, even one that involves a set choreography, fulfilling the intention of the dance involves some improvised activity in both learned and instinctual styles. Style is here defined as an adverbial "way" of dancing, which may or may not include its own special repertoire, that gives certain recognizable features or qualities to a dance performance that tell the audience something about its origin or method of creation. Those dance styles that can be taught to others will here be called "style $e_{\mathrm{t}}$." This is broadly equivalent to Armelagos and Sirridge's style ${ }_{1}$, although they characterize style ${ }_{1}$ as part of a "cohesive vocabulary and motivation choice" (Armelagos and Sirridge 1978, 131), and I would instead like to focus on the fact that it is a type of style that has been acquired through the teaching and learning process. Examples of styles that can be taught to others include (1) those from established dance genres or techniques, such as classical ballet, tap, hip-hop, contemporary, or character dance; and (2) styles that are attributable to a school, company, choreographer or composer, or teaching or performance method of dance, such as the Cechetti, Kirov, and neoclassical methods in ballet or the Graham or Horton techniques in modern dance.

In addition to styles that can be taught, individual styles exist that can be neither taught nor learned. Individual dance performers have been sought not just for their ability to convey a style $e_{t}$, but for the individual style that they bring to a performance as well. This kind of style will be called "style" where "i" stands for "individual." This is roughly equivalent to what Armelagos and Sirridge refer to as style ${ }_{2}$ (see Armelagos and Sirridge 1978, 131).

The "artistry" component of the idea of improvisation introduced here involves style in an important way. Style is what makes the improvisational activity "artistic" - in line with the artistic purposes of a dance-and not just part of the non-artistic physical necessities of a dance. Thus use of style in live dance performance demonstrates that ingrained, and trained, modes of agency are part and parcel of what a dance performer must learn in order to be able to function as a performing artist who can "act on his or her feet" during a live performance. 
Clark's embodied and extended mind theory can be folded into this account since it goes some way toward explaining how a performing artist can move in a body-involved way that incorporates, at least at some level, feedback from his or her interaction with a performance environment. A dancer responds to his or her performance environment, for example, while still moving in a learned or individual style that is chosen to fulfill the dance's artistic purposes. Repetitive practice in doing this can be as an artistic body schema, to make an analogy with the motor body schema mentioned by Clark. An artistic body schema would be one that involves the dancing body's natural and acquired plan for what to do and how to move that is shaped by years of artistic training and repetitive practice in artistic studio and performance environments.

The agency involved in improvisational artistry in live dance performance includes anything unplanned that trained, skilled dance performers end up doing in the course of live dance performance to either enhance a performance or to adjust for contingencies that threaten the artistic purpose of the dance. It involves the artist's ability to engage in "online" agency, which is just the sort of on-one's-feet, thinking-while-doing that Clark's theory provides (see Clark 2011, for example, at 118,145 , and 193). Indeed, the setting and conditions of a live performance always require the performer to be aware of his or her performing environment in an "online" way, making on-the-spot adjustments either to improve a performance or to correct a problem if something goes wrong.

There are contingencies in dance performances, for example, that are due to the fallibility and variability of what the human body can do on any given day. If a ballet dancer who is performing a series of sixteen turns in one place on the left foot, for example, has her left pointe shoe break after the eighth turn, she may choose to alter the choreography to do fewer turns or to do the turns on demi-pointe- a decision that is made consciously by the performer but without preperformance deliberation. The dancer will here use her trained skill as an artist in order to choose whichever alternative she believes will maintain the artistic integrity of the dance. Clark would describe this sort of choice as making use of a feedback loop that involves the dancer's awareness of an environmental change (the broken shoe shank) that is immediately incorporated into a new cognitive process (what we can here describe as an "agentive" process). In addition, the trained movement style involved in making this change a seamless one from left to right foot is a sort of agency that relies on natural and developed attributes of the dancer's style.

Another example involves environmental contingencies at a farther remove from the dancer's body. Here let us imagine that a dancer is standing in the center of the stage awaiting the entrance of her partner. The choreography instructs the dancer to greet her partner, who is to emerge from the upstage, left wing. Unexpectedly, however, a new stagehand has inadvertently blocked that wing with a footlight. The onstage dancer's bodily orientation is facing the upstage left wing where her partner is supposed to emerge but instead her partner comes bursting out of the downstage left wing, requiring an immediate physical adjustment on the part of the onstage dancer to face the partner who is emerging from the new entrance point. Here this bodily adjustment may be trained, but it is also so quick as to seem like a reflexive, instinctual response to an environmental change. Here the idea of an artistic body schema helps to explain why this change can be made so efficiently. Dancers sometimes use terms like "muscle memory," but it can also just be thought of as a kind of agentive, body-involved habit that has been pre-rehearsed so many times in various forms that no lengthy pre-performance deliberation is required. This accounts for how the dancer's "system" already knows how to function as a unit in this and other similar situations, thereby performing the new movement with the kind of spontaneity that this article has been attributing to "improvisational artistry." 


\section{Conclusion}

In conclusion, I have here supplemented theories of improvisation provided by dance philosophers and dance studies scholars in order to show that all live dance performance involves, to a greater or to a lesser degree, improvisational artistry. A dancer must make certain changes and adjustments in order to effectuate and complete the artistic purpose of a dance that takes place in a live, situated, and contingent performance environment. I have also shown that a dance performer's way of performing, through the use of style and what I have called a trained "artistic body schema," colors his or her intentional motor agency with a kind of artistry that constitutes part of the practice of dance performance. Further, I have shown that Clark's embodied and extended mind theory may assist our understanding of this agency by showing how embodied and extended processes are involved in the spontaneous choices a dancer makes during the course of performing a dance.

\section{Notes}

1. I thank David Davies, a philosopher of art at McGill University, for suggesting to me that "agency" would capture everything I needed to account for in my theory of improvisational artistry without needing to call it a theory of mind. He made this comment to me at the National American Society of Aesthetics meeting that took place in October 2012, where I presented an earlier version of this article.

2. One publication that routinely discusses improvisation from the experiential perspective of dance choreographers and performers is Contact Quarterly: A Journal of Dance Improvisation, Performance, and Contemporary Movement Arts. Web site: http://www.contactquarterly.com/cq/ cq_contactq.php. Another good resource for a general overview of types of improvisation in dance can be found in the "Improvisation" entry in the International Encyclopedia of Dance (Matheson 1998). Finally George E. Lewis and Benjamin Piekut (forthcoming) are editing the Oxford Handbook of Critical Improvisation Studies, which is due to be published in 2014. This is a two-volume set gathering authors from the arts, humanities, social sciences, and natural sciences.

3. For criticism of this adoption of Goodman for dance expression, see Margolis (1981).

4. Margolis's (1981) criticism of Sirridge and Armelagos's adoption of Goodman's theory of expression in dance also makes this criticism, pointing out that each individual dancing body has a "natural expressiveness" that is not reducible to movements or stylized movements that are codifiable in a notated score. See Margolis (1981, 421-2). Sirridge and Armelagos's response to Margolis's criticism can be found in Sirridge and Armelagos (1983).

5. In an earlier version of this article, I also addressed how Alva Noë's (2009) extended mind and Sean Gallagher's embodied mind theory (2005) might also be brought to bear on this question, but in my estimation, Clark's theory offered the least departure from the standard view of mind available in way that answered the questions of how body and environment are involved in improvisational agency that were sought. For an overview of additional embodied cognition studies, see Shapiro (2004).

6. For more opposing perspectives on the extended mind hypothesis, see Di Francesco (2010), Rupert (2004), and Adams and Aizawa (2001, 2010).

\section{Works Cited}

Adams, Fred, and Ken Aizawa. 2001. “The Bounds of Cognition.” Philosophical Psychology 14(1): 43-64.

- 2010. "Defending the Bounds of Cognition." In The Extended Mind, edited by Richard Menary, 67-80. Cambridge, MA: MIT Press.

Armelagos, Adina, and Mary Sirridge. 1978. "The Identity Crisis in Dance." The Journal of Aesthetics and Art Criticism 37(2): 129-39. 
Carter, Curtis L. 2000. "Improvisation in Dance." The Journal of Aesthetics and Art Criticism 58(2): 181-90.

Churchland, Patricia S. 2002. Brainwise: Studies in Neurophilosophy. Cambridge, MA: MIT Press.

Clark, Andy. 2011. Supersizing the Mind: Embodiment, Action, and Cognitive Extension. New York: Oxford University Press.

Dennett, Daniel. 1981. Brainstorms: Philosophical Essays on Mind and Psychology. Cambridge, MA: MIT Press.

De Spain, Kent. 2003. "Reports from the Inside of Improvisation.” In Taken by Surprise: A Dance Improvisation Reader, 27-38. Middletown, CT: Wesleyan University Press.

Di Francesco, Michele. 2010. "Extended Cognition and the Unity of Mind: Why We Are Not 'Spread into the World."' In Cartographies of the Mind: Philosophy and Psychology in Intersection, edited by Massimo Marraffa,Maria De Caro, and Francesco Ferretti, 211-28. Dordrecht, The Netherlands: Springer, 2010.

Fodor, Jerry. 1975. Language of Thought. New York: Thomas Y. Crowell Company, Inc. for Harvard University Press.

- 2009. "'Where is my mind?' : Review of Supersizing the Mind: Embodiment, Action and Cognitive Extension, by Andy Clark." London Review of Books 31(3): 13-5. http://www.lrb.co. uk/v31/no3/jerry-fodor/where-is-my-mind, accessed May 30, 2012.

Foster, Susan Leigh. 2003. "Taken by Surprise: Improvisation in Dance and Mind." In Taken by Surprise: A Dance Improvisation Reader, 3-12. Middletown, CT: Wesleyan University Press.

Gallagher, Sean. 2005. How the Body Shapes the Mind. Oxford, UK: Oxford University Press.

Goldman, Danielle. 2010. I Want to Be Ready. Ann Arbor, MI: The University of Michigan Press.

Goodman, Nelson. 1976. Languages of Art: An Approach to a Theory of Symbols. Indianapolis, IN: Hackett Publishing Company Inc.

Haugeland, John. 1998. "Mind embodied and embedding." In Having Thought: Essays in the metaphysics of mind, edited by John Haugeland, 207-37. Cambridge, MA: Harvard University Press.

Hill, Constance Valis. 2003. "Stepping, Stealing, Sharing, and Daring." In Taken by Surprise: A Dance Improvisation Reader, edited by Ann Cooper Albright and David Gere, 89-102. Middletown, CT: Wesleyan University Press.

Lewis, George E., and Benjamin Piekut, editors. Forthcoming. Oxford Handbook of Critical Improvisation Studies. Oxford, UK: Oxford University Press.

Margolis, Joseph. 1981. "The Autographic Nature of the Dance." The Journal of Aesthetics and Art Criticism 39(4): 419-27.

Matheson, Katy. 1998. "Improvisation." In International Encyclopedia of Dance: A Project of Dance Perspectives, edited by Selma Jean Cohen and Dance Foundation, Inc. New York: Oxford University Press.

Noë, Alva. 2009. Out of Our Heads. New York: Hill \& Wang.

Rupert, Robert D. 2004. "Challenges to the Hypothesis of Extended Cognition." The Journal of Philosophy 101(8): 389-428,

Searle, John. 1983. Intentionality: An Essay in the Philosophy of Mind. Cambridge, UK: Cambridge University Press.

Shapiro, Lawrence. 2004. The Mind Incarnate. Cambridge, MA: MIT Press.

Sirridge, Mary, and Adina Armelagos. 1977. “The In's and Out's of Dance: Expression as an Aspect of Style." The Journal of Aesthetics and Art Criticism 36(1): 15-24.

— 1983. "The Role of 'Natural Expressiveness' in Explaining Dance." The Journal of Aesthetics and Art Criticism 41(3): 301-7.

Zaporah, Ruth. 2003. "A Body with a Mind of Its Own." In Taken by Surprise: A Dance Improvisation Reader, 22-6. Middletown, CT: Wesleyan University Press. 
Copyright of Dance Research Journal is the property of Cambridge University Press and its content may not be copied or emailed to multiple sites or posted to a listserv without the copyright holder's express written permission. However, users may print, download, or email articles for individual use. 